\title{
Fetal gender ratio in recurrent miscarriages
}

This article was published in the following Dove Press journal:

International Journal of Women's Health

18 July 2011

Number of times this article has been viewed

\author{
Anna Del Fabro' \\ Lorenza Driul' \\ Omar Anis' \\ Ambrogio P Londero' \\ Serena Bertozzi ${ }^{2}$ \\ Livio Bortotto 3 \\ Diego Marchesoni' \\ 'Clinic of Obstetrics and Gynecology, \\ ${ }^{2}$ Clinic of Surgery, ${ }^{3}$ Unit of \\ Genetics, University Hospital of \\ Udine, Udine, Italy
}

Background: The purpose of this study was to evaluate the gender ratio and incidence of chromosomal anomalies in the products of conception (POC) from recurrent miscarriages.

Methods: We determined the karyotypes of POC from patients with recurrent spontaneous miscarriages between 1999 and 2009.

Results: In total, 313 specimens were successfully karyotyped, with a median gestational age of 10 weeks at miscarriage (interquartile range 8-13); 199 (64\%) were females and 114 (36\%) were males. In total, 121 (39\%) had abnormal karyotypes, the most prevalent of which were chromosome 21 and 16 trisomies, triploidy, and monosomy X.

Conclusion: Our findings suggest that female POC might be more susceptible to recurrent miscarriages than male ones during embryogenesis, implantation, and initial fetal development.

Keywords: fetal gender, recurrent miscarriages, karyotype anomalies

\section{Introduction}

Miscarriage is the most common complication of pregnancy, defined as the spontaneous termination of pregnancy itself before the fetus has attained the stage of viability. Although only $15 \%$ of miscarriages are clinically recognized, total reproductive losses are closer to $50 \%$ of conceptions, and this complication is observed in about $1 \%-5 \%$ of couples trying to conceive, ${ }^{1}$ with a rising incidence.

Miscarriages can be sporadic or recurrent. ${ }^{2,3}$ Recurrent miscarriage, which traditionally corresponds to the termination of three or more consecutive pregnancies, has recently been defined in the guidelines of the American Society of Reproductive Medicine as the loss of two or more consecutive pregnancies. ${ }^{4}$ The etiology of recurrent miscarriage includes genetic abnormalities, autoimmune-related conditions, structural abnormalities, infections, and endocrine disorders, and is unknown in a significant number of miscarriages. Although chromosomal anomalies are identified in about $50 \%-60 \%$ of all miscarriages, they seem to occur less frequently in the products of conception (POC) from recurrent abortions than in those from sporadic abortions. ${ }^{5,6}$

Because the gender ratio of live births in the human species is approximately 1.05 , with males being slightly more represented, there might also be a gender rate distortion in spontaneous abortions, so that female POCs may be more susceptible to abortion than male ones. ${ }^{7}$ We investigated the karyotypes of abortuses in recurrent miscarriages, considering also gestational and maternal age at miscarriage, and evaluated the gender ratio of the miscarried POC and the incidence of chromosomal anomalies in the POC from recurrent miscarriage.

Correspondence:Ambrogio P Londero

Clinic of Obstetrics and Gynecology,

Piazzale SM della Misericordia,

15-33 100 Udine, Italy

Tel +390432559635

$\mathrm{Fax}+390432559641$

Email ambrogio.londero@gmail.com 


\section{Materials and methods}

We performed a retrospective analysis of recurrent miscarriages that occurred between January 1999 and June 2009 in patients admitted to the Department of Obstetrics and Gynecology at the University Hospital of Udine. We excluded material from first miscarriages, considering these more likely to be due to sporadic loss, as well as that from miscarriages at the end of gestational week 22 and from twin pregnancies.

We investigated the gender ratio of the POC, the incidence of miscarriage in relation to gestational age, frequency and type of chromosomal anomalies in abortuses, and incidence of chromosomal anomalies in male and female POC.

Chromosomal and cytogenetic analysis of recurrent miscarriages was carried out by the Department of Genetics at the University Hospital of Udine. Villi were isolated from POC specimens and cells were extracted to be cultured for karyotype analysis. Other specimen sources for karyotype analysis were the skin of miscarried POC and the placenta. We collected and examined all tissue samples after accurate removal of maternal blood and decidual tissue. Analysis of G-banded metaphase chromosomes was performed on cultured tissue samples using standard procedures. Karyotypes were described according to the 2005 guidelines of the International System for Human Cytogenetic Nomenclature.

\section{Statistical analysis}

The statistical analysis was performed using $\mathrm{R}$ (version 2.10.1) and $P<0.05$ was considered to be statistically significant. The $t$-test, Chi-square test, and Fisher Exact test were used as appropriate.

\section{Results}

A total of 313 POCs were included in the final analysis, miscarried at a median gestational age of 10 weeks (interquartile range [IQR] 8-13), by women of median age 35 years (IQR 31-39). Female POC were significantly more represented than male ones ( $64 \%$ versus $36 \%, P<0.05$ ), even after stratification for gestational age (Figure 1), although statistical significance was reached only with regard to the whole population and gestational week 4-10 $(P<0.001)$. The causes of miscarriage are reported separately in Table 1 , and the most frequent was idiopathic miscarriage.

Karyotype abnormalities explained miscarriage in 121 cases $(39 \%)$, but could not account for miscarriage in 13 cases $(4 \%)$. The most common anomalies were autosomal trisomies $(84 / 134,63 \%)$, which were more frequently observed in males than in females (38\% versus $21 \%, P<0.05$, Figure 1$)$. The most frequent of them were trisomy $21(\mathrm{n}=20)$ and trisomy $16(\mathrm{n}=15)$. Trisomies 13 , 15,16 , and 21 were more common in samples originating from males, whereas trisomies $2,3,4,5,18,20$, and 22 were more common among those with a female karyotype (Figure 2). Triploidy was the second most frequent abnormality in POC (21/134, 16\%) of either gender. Monosomy and tetraploidy were found, respectively, in eight $(6 \%)$ and four (3\%) tissue samples, the latter being more prevalent in males than in females.

\section{Discussion}

Our study found that in 313 karyotyped POC, 199 (64\%) were females and $114(36 \%)$ males, the difference being statistically significant $(P<0.05)$ and suggesting a distorted gender ratio. Moreover, the most common anomalies were chromosome 21 and 16 trisomies, triploidy, and monosomy $\mathrm{X}$, with trisomies having a higher incidence in males than in females.

The male to female ratio of births is known to be slightly in favor of males, and despite the lack of literature about gender ratio and miscarriages, these data are confirmed also in our population, where the male to female ratio was 1.06 (Table 2). However, this ratio seems to have been lowering worldwide in favor of female births over the past few decades in Europe, the US, and Japan, ${ }^{8,9}$ probably due to increased prenatal vulnerability of male fetuses after gestational week $12 .{ }^{10,11}$ Also, in our population, of 72 intrauterine fetal deaths after gestational week $23,58 \%$ were males and $42 \%$ were females $(P<0.05)$, but these represented only a minority of adverse events ( $0.5 \%$ of deliveries). In fact, most of the miscarriages affect the first gestational trimester which is probably caused by karyotype anomalies. Furthermore, the presence of gender ratio distortion in miscarriages may be the cause of the higher prevalence of male newborns. ${ }^{5}$

The median maternal age in our population was 35 years, which could account for the high prevalence of chromosomal abnormalities. To reduce contamination bias from maternal cells in this retrospective study, accurate selection of specimens for culture was performed by an experienced geneticist. Moreover, the risk of contamination was low for fetal skin and placenta samples at gestational weeks 11-22.

According to the current literature, autosomal trisomies are the most common karyotype anomaly, followed by triploidies in both genders, ${ }^{12}$ being significantly more frequent in male $(50 \%, 57 / 114)$ than in female POC $(32 \%$, $64 / 199) \cdot{ }^{13,14}$ 


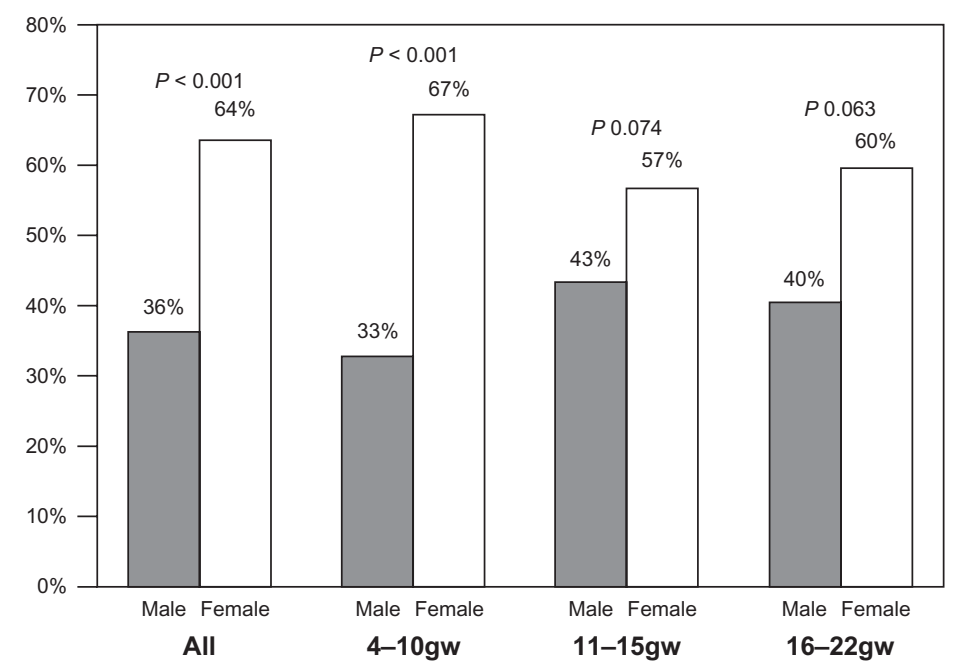

Figure I Male to female ratio in recurrent miscarriages $(n=3 / 3)$ by gestational age.

Table I Reasons for miscarriage in normal karyotypes and abnormal karyotypes identified in products of conception in 3 I 3 recurrent abortions

\begin{tabular}{|c|c|c|c|c|}
\hline & All population & Females & Males & $P$ \\
\hline Idiopathic miscarriage & $49 \%(152 / 313)$ & $57 \%(113 / 199)$ & $34 \%(39 / 114)$ & $<0.05$ \\
\hline 4-10 weeks & $44 \%(74 / 168)$ & $55 \%(62 / 1 / 3)$ & $22 \%(12 / 55)$ & $<0.05$ \\
\hline II-I5 weeks & $42 \%(38 / 90)$ & $49 \%(25 / 5 I)$ & $33 \%(13 / 39)$ & 0.135 \\
\hline 16-22 weeks & $72 \%(34 / 47)$ & $71 \%(20 / 28)$ & $74 \%(14 / 19)$ & 0.865 \\
\hline Other maternal pathologies & $2 \%(6 / 3 \mid 3)$ & $2 \%(4 / 199)$ & $2 \%(2 / 114)$ & 0.874 \\
\hline 4-10 weeks & $2 \%(3 / 168)$ & $3 \%(3 / 113)$ & $0 \%(0 / 55)$ & 0.223 \\
\hline $11-15$ weeks & $1 \%(1 / 90)$ & $0 \%(0 / 5 \mathrm{I})$ & $3 \%(1 / 39)$ & 0.250 \\
\hline I6-22 weeks & $4 \%(2 / 47)$ & $4 \%(1 / 28)$ & $5 \%(1 / 19)$ & 0.778 \\
\hline Infection/cervical incontinence/PROM & $2 \%(5 / 3 \mid 3)$ & $1 \%(2 / 199)$ & $3 \%(3 / 114)$ & 0.269 \\
\hline 4-10 weeks & NA & NA & NA & \\
\hline II-15 weeks & $1 \%(1 / 90)$ & $0 \%(0 / 5 \mathrm{I})$ & $3 \%(1 / 39)$ & 0.250 \\
\hline 16-22 weeks & $9 \%(4 / 47)$ & $7 \%(2 / 28)$ & $11 \%(2 / 19)$ & 0.683 \\
\hline Trisomies & $27 \%(84 / 3 \mid 3)$ & $21 \%(4 I / 199)$ & $38 \%(43 / I \mid 4)$ & $<0.05$ \\
\hline 4-10 weeks & $36 \%(60 / 168)$ & $26 \%(29 / 113)$ & $56 \%(31 / 55)$ & $<0.05$ \\
\hline II-15 weeks & $24 \%(22 / 90)$ & $22 \%(I I / 5 I)$ & $28 \%(11 / 39)$ & 0.468 \\
\hline 16-22 weeks & NA & NA & NA & \\
\hline Monosomy X & $3 \%(8 / 3 \mid 3)$ & $4 \%(7 / 199)$ & $1 \%(|/| \mid 4)$ & 0.154 \\
\hline 4-10 weeks & $2 \%(3 / 168)$ & $3 \%(3 / 113)$ & $0 \%(0 / 55)$ & 0.223 \\
\hline II-I5 weeks & $4 \%(4 / 90)$ & $6 \%(3 / 51)$ & $3 \%(1 / 39)$ & 0.449 \\
\hline 16-22 weeks & $2 \%(1 / 47)$ & $4 \%(1 / 28)$ & $0 \%(0 / 19)$ & 0.405 \\
\hline Triploidy & $7 \%(2|/ 3| 3)$ & $5 \%(9 / 199)$ & $11 \%(12 / 114)$ & $<0.05$ \\
\hline $4-10$ weeks & $7 \%(12 / 168)$ & $5 \%(6 / 1 / 3)$ & $11 \%(6 / 55)$ & 0.186 \\
\hline $11-15$ weeks & $9 \%(8 / 90)$ & $6 \%(3 / 5 I)$ & $13 \%(5 / 39)$ & 0.252 \\
\hline 16-22 weeks & $2 \%(1 / 47)$ & $0 \%(0 / 28)$ & $5 \%(1 / 19)$ & 0.220 \\
\hline Tetraploidy & $1 \%(4 / 3 \mid 3)$ & $2 \%(3 / 199)$ & $1 \%(I / I \mid 4)$ & 0.633 \\
\hline 4-10 weeks & $1 \%(2 / 168)$ & $2 \%(2 / 113)$ & $0 \%(0 / 55)$ & 0.321 \\
\hline II-15 weeks & $2 \%(2 / 90)$ & $2 \%(I / 5 I)$ & $3 \%(1 / 39)$ & 0.847 \\
\hline 16-22 weeks & NA & NA & NA & \\
\hline Separate rearrangements* & $5 \%(|7 / 3| 3)$ & $5 \%(10 / 199)$ & $6 \%(7 / 114)$ & 0.675 \\
\hline 4-10 weeks & $7 \%(12 / 168)$ & $6 \%(7 / 1 / 3)$ & $9 \%(5 / 55)$ & 0.494 \\
\hline II-I5 weeks & $2 \%(2 / 90)$ & $2 \%(I / 5 I)$ & $3 \%(1 / 39)$ & 0.847 \\
\hline 16-22 weeks & $6 \%(3 / 47)$ & $7.14 \%(2 / 28)$ & $5 \%(1 / 19)$ & 0.796 \\
\hline Fetal malformation & $5 \%(|6 / 3| 3)$ & $5 \%(10 / 199)$ & $5 \%(6 / 114)$ & 0.927 \\
\hline 4-10 weeks & $1 \%(2 / 168)$ & $1 \%(1 / 113)$ & $2 \%(1 / 55)$ & 0.601 \\
\hline II-I5 weeks & $13 \%(12 / 90)$ & $14 \%(7 / 5 \mid)$ & $13 \%(5 / 39)$ & 0.900 \\
\hline 16-22 weeks & $4 \%(2 / 47)$ & $7 \%(2 / 28)$ & $0 \%(0 / 19)$ & 0.234 \\
\hline
\end{tabular}

Notes: *Separate rearrangements: 46, XX, -I, +der(I),t(1;18);46, XX,-12, +der(I2),t(II;12);46, XX, der(4),t(4;8)mat; 46, XY, $-5,+\operatorname{der}(5), \mathrm{t}(5: 7) ; 46, X X, \operatorname{var}(15 \mathrm{p}+), \operatorname{var}(15 \mathrm{p}+)$ PCD.

Abbreviations: PROM, premature rupture of membranes; NA, not available. 


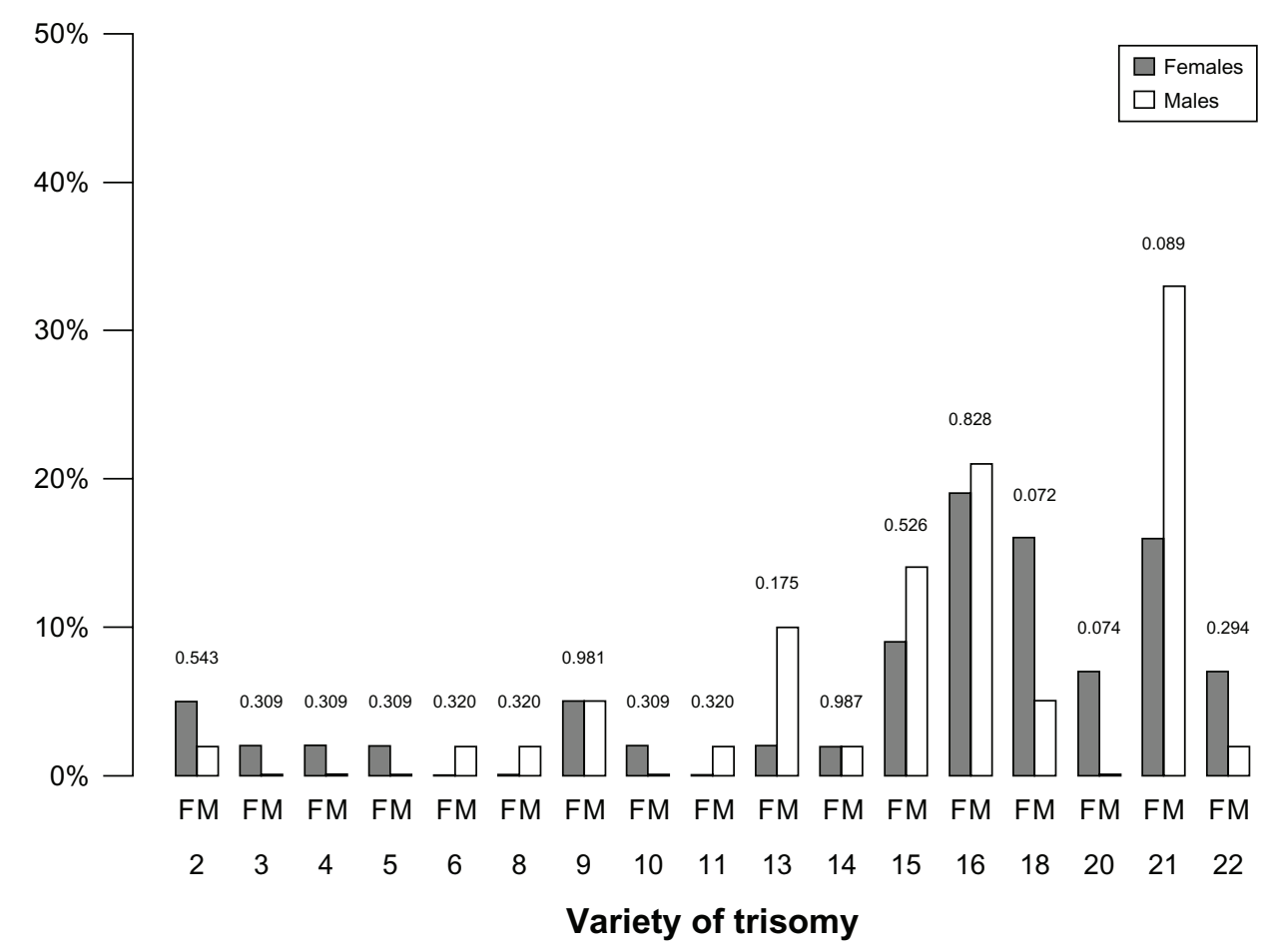

Figure 2 Trisomic distribution in male and female products of conception.

Despite the crucial role of chromosomal anomalies in recurrent miscarriages, their relatively low incidence (39\%) suggests that other mechanisms may be responsible for recurrent miscarriages..$^{15}$ According to evolutionary theory and the Dawkin's Selfish Gene theory, sexually antagonistic genes may be expressed during early genetic determination of gender. ${ }^{16,17}$ An example of sexual gene antagonism may be found in the butterfly, Acrea encedon, which has a gender imbalance of $97 \%$ favoring females as a result of sex chromosome drive. ${ }^{16}$

In the $1980 \mathrm{~s}$, McGrath and Solter tried to create a uniparental mouse, ${ }^{18}$ finding the embryo from two mothers to be properly organized, but was not able to develop a functional placenta, and the embryo from two fathers was found to be disorganized despite the development of a large and healthy

Table 2 Gender distribution of live births at our clinic between $200 \mathrm{I}$ and 2008

\begin{tabular}{|c|c|c|c|}
\hline Year & Female & Male & $P$ \\
\hline 2001 & $47 \%(820 / 1730)$ & $53 \%(9 / 0 / 1730)$ & 0.423 \\
\hline 2002 & $50 \%(894 / 1804)$ & $50 \%(910 / 1804)$ & 0.254 \\
\hline 2003 & $46 \%(848 / / 833)$ & $54 \%(985 / 1833)$ & 0.061 \\
\hline 2004 & $49 \%(868 / 1773)$ & $51 \%(905 / 1773)$ & 0.556 \\
\hline 2005 & $49 \%(901 / 1840)$ & $51 \%(939 / 1840)$ & 0.541 \\
\hline 2006 & $49 \%(875 / 1793)$ & $51 \%(9 / 8 / 1793)$ & 0.651 \\
\hline 2007 & $49 \%(880 / 1796)$ & $51 \%(916 / 1796)$ & 0.528 \\
\hline 2008 & $47 \%$ (854/I799) & $53 \%(945 / 1799)$ & 0.451 \\
\hline
\end{tabular}

placenta. The presence of genetic sexual antagonism may explain the higher prevalence of female POC, because the imprinted male genes of the placenta are slightly more prone to favor a male embryo than a female one.

In our opinion, during the first trimester of pregnancy, miscarried female POC may be partially due to imprinted paternal genes. Further studies are required to confirm this theory, which is based on conflict in maintaining the equilibrium between genders in mammalian species and imprinting influences during intrauterine life. ${ }^{19}$

Despite the retrospective nature of our study, and the limited clinical information it offers, the large number of cases strengthens our data. We conclude that female embryos are more prone to be miscarried than male ones in recurrent miscarriages, and that more research should be carried out to study the influence of imprinting on intrauterine life.

\section{Disclosure}

The authors report no conflicts of interest in this work.

\section{References}

1. Rai R, Regan L. Recurrent miscarriage. Lancet. 2006;368(9535):601-611.

2. Kline J, Stein Z, Susser M. Conception to Birth: epidemiology of Prenatal Development. Monographs in Epidemiology and Biostatistics. New York, NY: Oxford University Press; 1989.

3. Wilcox AJ, Weinberg CR, O'Connor JF, et al. Incidence of early loss of pregnancy. N Engl J Med. 1988;319(4):189-194. 
4. Practice Committee of the American Society for Reproductive Medicine. Definitions of infertility and recurrent pregnancy loss. Fertil Steril. 2008;89(6): 1603 .

5. Kano T, Mori T, Kimura A. Gender ratio distortion in abortuses and live births from patients with recurrent spontaneous abortion. Am J Reprod Immunol. 2009;62(3):125-127.

6. Takakuwa K, Asano K, Arakawa M, Yasuda M, Hasegawa I, Tanaka K. Chromosome analysis of aborted conceptuses of recurrent aborters positive for anticardiolipin antibody. Fertil Steril. 1997;68(1):54-58.

7. McMillen MM. Differential mortality by sex in fetal and neonatal deaths. Science. 1979;204(4388):89-91.

8. Ohmi H, Hirooka K, Mochizuki Y. Reduced ratio of male to female births in Japan. Int J Epidemiol. 1999;28(3):597.

9. Davis DL, Gottlieb MB, Stampnitzky JR. Reduced ratio of male to female births in several industrial countries: a sentinel health indicator? JAMA. 1998;279(13):1018-1023.

10. Ohmi H, Hirooka K, Mochizuki Y, Hata A. The male/female ratio of spontaneous fetal deaths and low birthweight in Japan. Pediatr Int. 2008;50(2):262-263.

11. Mizuno R. The male/female ratio of fetal deaths and births in Japan. Lancet. 2000;356(9231):738-739.
12. Carp H, Toder V, Aviram A, Daniely M, Mashiach S, Barkai G. Karyotype of the abortus in recurrent miscarriage. Fertil Steril. 2001;75(4):678-682.

13. Griffin DK, Abruzzo MA, Millie EA, Feingold E, Hassold TJ. Sex ratio in normal and disomic sperm: evidence that the extra chromosome 21 preferentially segregates with the Y chromosome. Am J Hum Genet. 1996;59(5):1108-1113.

14. Mokhtar MM, el Aziz AMA, Nazmy NA, Mahrous HS. Cytogenetic profile of Down syndrome in Alexandria, Egypt. East Mediterr Health J. 2003;9(1-2):37-44.

15. Marquard K, Westphal LM, Milki AA, Lathi RB. Etiology of recurrent pregnancy loss in women over the age of 35 years. Fertil Steril. 2010;94(4):1473-1477.

16. Ridley M. Genome: The Autobiography of a Species in 23 Chapters. New York, NY: Harper Collins Publishers; 2000.

17. Dawkins R. The Selfish Gene. Oxford, UK: Oxford University Press; 1976.

18. McGrath J, Solter D. Completion of mouse embryogenesis requires both the maternal and paternal genomes. Cell. 1984;37(1):179-183.

19. Majerus M, Amos WH, Hurst G. Evolution: The Four Billion Year War Essex, UK: Longman Publishing Group; 1996.
International Journal of Women's Health

\section{Publish your work in this journal}

The International Journal of Women's Health is an international, peerreviewed open-access journal publishing original research, reports, reviews and commentaries on all aspects of women's healthcare including gynecology, obstetrics, and breast cancer. Subject areas include: Chronic conditions (migraine headaches, arthritis, osteoporosis);

\section{Dovepress}

Endocrine and autoimmune syndromes; Sexual and reproductive health; Psychological and psychosocial conditions. The manuscript management system is completely online and includes a very quick and fair peer-review system. Visit http://www.dovepress.com/ testimonials.php to read real quotes from published authors. 